\title{
ZONIFICACIÓN DE LA SUSCEPTIBILIDAD A DESLIZAMIENTOS INTEGRANDO UN ENFOQUE SOCIAL, EN LA CUENCA DEL RÍO VIEJO, PURISCAL
}

\author{
Angela Marcela Suárez (2010)
}

En Costa Rica, los deslizamientos al igual que las inundaciones, son los eventos que más afectan a la población debido a su recurrencia e impacto a nivel local; sin embargo la mayoría de los lugares solo cuentan con una zonificación de deslizamientos a gran escala. La cuenca del río Viejo en Puriscal es uno de los lugares más afectados por deslizamientos. En esta investigación se propone una zonificación de la susceptibilidad a deslizamientos para esta cuenca como producto de un diálogo de saberes de los "expertos" y de representantes de esta comunidad.

La zonificación se inicia con la elaboración de mapas de factores que de acuerdo con la opinión técnica y de la comunidad, condicionan la ocurrencia de deslizamientos; estos son: geología, geomorfologia, usos de la tierra, pendiente, disparo por sismos, humedad, disparo por lluvias, distancia a partir de alineamientos tectónicos, distancia a partir de corrientes de agua, distancia a partir de vías.

También se realizó un mapa de inventario de deslizamientos con el fin de conocer su distribución y densidad, el cual sirvió para la determinación de los pesos de cada uno de los mapas de factores a partir del método estadístico denominado "Pesos de evidencia"; asimismo, se hizo la ponderación de estos mapas a partir de métodos heurísticos (basados principalmente en la opinión de la comunidad y de los "expertos").

Luego, se plantearon diferentes escenarios de acuerdo a la inclusión y ponderación de cada una de las variables a partir de ios dos métodos, y se escogió uno que representa de la mejor forma la susceptibilidad por deslizamiento de acuerdo con el mapa de inventario y las observaciones de campo.

Teniendo en cuenta que el trabajo se desarrolló de forma conjunta con la comunidad, el mapa es un producto del cual la comunidad se siente partícipe, aumentando la probabilidad de que sea una herramienta útil para procesos de ordenamiento territorial y de gestión del riesgo que se desarrollen a futuro.

Se confirmó principalmente la importancia del estudio geomorfológico dentro de la evaluación de la susceptibilidad a deslizamiento en él. 